Research Article

\title{
Cytototoxic Activity of Liposomal Formulations of Quercetin on Ovarian Cancer cells and Normal Human Embryonic Kidney cells
}

\author{
Shreya Banerjee ${ }^{1,2}$, Debasis Dutta ${ }^{2}$, Shila Elizabeth Besra ${ }^{1^{*}}$ \\ 1. Central Instrumentation Facility and Cancer Biology \& Inflammatory Disorder Division, CSIR- Indian Institute of Chemical Biology, 4 \\ Raja S.C. Mullick Road, Kolkata, West Bengal, India. \\ 2.Pharmaceutics Division, Department of Pharmacy, School of Health Sciences, NSHM Knowledge Campus, Kolkata-Group of \\ Institutions, 124 (60), B. L. Saha Road, Tara Park, Behala, Kolkata, West Bengal, India. \\ *Corresponding author's E-mail: shilabesra@iicb.res.in
}

Received: 10-09-2020; Revised: 23-11-2020; Accepted: 30-11-2020; Published on: 15-12-2020. \begin{abstract}
Quercetin is a flavonoid of natural origin known to have anti-cancer and antioxidant properties. We evaluated effect of liposomal formulations of quercetin on pro-monocytic human myeloid leukemia cell line in our previous work. However, effect of liposomal formulations of Quercetin (QTLF) on human ovarian cancer SKOV-3 and normal human embryonic kidney cells (HEK293T) has not been reported. Therefore, we investigated the cytotoxic effect of QTLF in SKOV-3 as well as Hek293T cell lines. The cytotoxic effect of QTLF was observed by MTT assay. The data reveal that QTLF significantly inhibited the growth of metabolically active cells in a time and concentration dependent manner, whereas insignificantly inhibited the growth of normal cells in a time and concentration dependent manner which reveals the toxic effect of QTLF towards cancer cells only and not in the normal human kidney cells. Thus, it can be considered safe for administration into the human body. Furthermore, mechanistic work needed to prove that the solubility enhancement of drug produces a more potent form of the Novel Drug Delivery System that can be used to modify the pharmacokinetic and pharmacodynamics properties of an insoluble compound.
\end{abstract}

Keywords: Liposome, Quercetin, Cancer, Cytotoxicity, Novel Drug Delivery.

QUICK RESPONSE CODE $\rightarrow$

DOI:

10.47583/ijpsrr.2020.v65i02.013

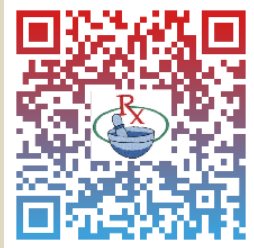

DOI link: http://dx.doi.org/10.47583/ijpsrr.2020.v65i02.013

\section{INTRODUCTION}

uercetin (2-(3,4-dihydroxyphenyl)-3,5,7-trihydroxy$4 \mathrm{H}$-chromen-4-one) is a natural flavonoid compound with nutritional values and potential anti-proliferative effect. In spite of being a compound of notable anti-cancer properties, quercetin has limited gastrointestinal solubility and bioavailability which reduces its pharmacological potential. To overcome these shortcomings, novel carriers can be employed. 1 Nanomedicines are small systems with high surfacevolume ratio and involve pharmaceutical compounds with modified permeability and an approach of targeted therapy. Hydrophobic drugs have shown to have better stability and longer release when administered via novel delivery methods. Some nanotechnology-based systems are polymeric micelles, liposomes, dendrimers, and nanoparticles. 2,3 Liposomes are sphere shaped phospholipid bilayer membrane carriers which is capable of incorporating wide ranges of drugs and also ensures biocompatibility, selectivity and stability in human body. Low particle size of liposomes ensures its accumulation in tumor tissues, phenomenon known as enhanced permeability retention (EPR), making it the perfect carrier for cytotoxic drugs. ${ }^{4}$ Cancer is a well-known and serious pathological condition occurring mostly as a result of genetic abnormalities which leads to an unstoppable growth of cells. Lumps of genetically similar cells form tumors which can be benign or malignant. In cancerous cells, loss of normal functions such as accurate DNA replication, control over the cell cycle, orientation and adhesion within tissues, and interaction with protective cells of the immune system is normally observed 5,6 . Currently, there are certain treatment methods followed for cancer, namely, surgical method, radiation therapy and chemotherapy. Conventional chemotherapy, although a very effective method, have the drawbacks of nonselectivity, thereby affecting healthy cells and low accessibility at the site of tumour. However, the emergence of nanotechnology in the past few years have hinted at a prospect of a safer and highly efficient way of cancer therapy. ${ }^{7}$ Ovarian cancer is a type of malignancy which is a major cause of death for women. It is not only limited to ovary but also includes fallopian tube and primary peritoneal cancers. ${ }^{8}$ It is a threat because there's no method of early detection leading to late diagnosis. Oral contraceptives have been widely used for treatment only. So, it is imperative to work on more pharmaceutical compounds which would successfully treat the condition. ${ }^{9}$, 10, 11 HEK293T cells are immortalized human embryonic kidney cells, expressing SV40T antigen gene, which are widely used for toxicological testing of drugs and in cancer research. ${ }^{12}$ So, this study focuses on the development and 
evaluation of a liposomal formulation (QTLF) of a drug of natural origin named Quercetin and thereby analyzing its activity on human ovarian cancer cell line SKOV-3 and human embryonic kidney cell line HEK293T.

\section{MATERIALS AND METHODS}

\section{Chemicals used}

Quercetin (Loba Chemie, India), Ethanol absolute (Balaji Drugs Pvt. Limited, India), Chloroform (Balaji Drugs Pvt. Limited, India), Soya Lecithin (Himedia, India), Hydrogen Chloride (Rankem , Avantor, India), Potassium chloride, Potassium di-hydrogen phosphate, Sodium hydroxide (Merck Specialties Pvt. Ltd., Mumbai), DMEM media (Gibco), Foetal calf serum (FCS), Penicillin-Streptomycin, Gentamycin, MTT [3-(4,5-dimethylthiozol-2-il) 2,5-2,5dipheniltetrazoliumbromide], Dimethyl sulphoxide (DMSO).

\section{Cell Culture}

Human Ovarian Cancer cell line (SKOV-3) and Human Embryonic Kidney cell line (HEK293T) cell lines were obtained from National Centre for Cell Science, Pune for in-vitro studies. These cells were sub-cultured as per the requirement of the experiment at an initial concentration of $1 \times 10^{6}$ cells $/ \mathrm{ml}$. SKOV-3 and HEK293T cells were maintained in sterile DMEM medium supplemented with $10 \%$ heat activated FCS. Cultures were maintained at $37^{\circ} \mathrm{C}$ in a humified atmosphere containing $5 \% \mathrm{CO}_{2}$ in air.

\section{Preparation of Standard Curve of Quercetin in Ethanol at 370nm}

$50 \mathrm{mg}$ Quercetin was measured and taken into a $50 \mathrm{ml}$ volumetric flask. $50 \mathrm{ml}$ ethanol was added into the flask to solubilise the Quercetin (QTF) properly and concentration becomes $1000 \mu \mathrm{g} / \mathrm{ml}$. $5 \mathrm{ml}$ of solution was taken and dissolved in $50 \mathrm{ml}$ ethanol to make $100 \mu \mathrm{g} / \mathrm{ml}$. From this stock solution different concentrations of QTF solution i.e., $2 \mu \mathrm{g} / \mathrm{ml}, 4 \mu \mathrm{g} / \mathrm{ml}, 6 \mu \mathrm{g} / \mathrm{ml}, 8 \mu \mathrm{g} / \mathrm{ml}$ and $10 \mu \mathrm{g} / \mathrm{ml}$ were prepared using ethanol. The Quercetin solutions were scanned in UV Visible Spectrophotometer (UV 1800, Shimadzu, Japan) at 200-400 nm. Then absorbance was measured by UV Spectrophotometry at $370 \mathrm{~nm}$ wavelength using ethanol as blank.

\section{Preparation of Standard Curve of Quercetin in Phosphate buffer pH 7.4 at $370 \mathrm{~nm}$}

$25 \mathrm{mg}$ quercetin was measured and taken in a $100 \mathrm{ml}$ volumetric flask. Around $1 \mathrm{ml}$ of ethanol was added into the flask to solubilize the Quercetin properly and the volume was made up to $100 \mathrm{ml}$ with phosphate buffer solution $\mathrm{pH}$ 7.4 to make a concentration of $250 \mu \mathrm{g} / \mathrm{ml}$. From this stock solution different concentrations of QTF solution $5 \mu \mathrm{g} / \mathrm{ml}$, $10 \mu \mathrm{g} / \mathrm{ml}, 15 \mu \mathrm{g} / \mathrm{ml}, 20 \mu \mathrm{g} / \mathrm{ml}$ and $25 \mu \mathrm{g} / \mathrm{ml}$ were prepared using phosphate buffer $\mathrm{pH}$ 7.4. The quercetin solution was scanned in UV Visible spectrophotometer (UV 1800, Shimadzu, Japan) at 200-400nm. Then absorbance was measured by UV Spectrophotometry at $370 \mathrm{~nm}$ wavelength using phosphate buffer as blank ${ }^{13}$.

\section{Preparation of Liposomal Formulations of Quercetin}

Blank liposomes were prepared using lipid and the organic solvents only and the consistency of the formulation was checked. After that lipid mixture of phospholipid and Quercetin was dissolved in two organic solvents which were present in a fixed ratio and shaken continuously for some time under a temperature of $50-55^{\circ} \mathrm{C}$. The film formed was then hydrated by an aqueous buffer solution and the dispersion was then sonicated. The liposome dispersion was transferred into a tube and then placed in a bath Sonicator. Controlling the temperature of the lipid dispersion is usually easier in this method. The dispersion was then kept in a sterile container and stored for evaluation ${ }^{14}$.

Table 1: Formulations of Liposome Preparation

\begin{tabular}{|c|c|c|c|c|c|c|c|c|}
\hline INGREDIENT & QTLF1 & QTLF2 & QTLF3 & QTLF4 & QTLF5 & QTLF6 & QTLF7 & QTLF8 \\
\hline Quercetin/mg & 80 & 75 & 150 & 270 & 200 & 234 & 270 & 200 \\
\hline Soya Lecithin/mg & 20 & 25 & 20 & 20 & 20 & 20 & 40 & 30 \\
\hline Ethanol/ ml & 10 & 10 & 10 & 10 & 10 & 10 & 10 & 10 \\
\hline Chloroform/ ml & 10 & 10 & 10 & 10 & 10 & 10 & 10 & 10 \\
\hline
\end{tabular}

\section{Drug Identification Study by FTIR}

Fourier Transform Infrared Spectroscopy (FTIR) of pure drug using FTIR spectrophotometer. The sample is prepared with potassium bromide and data are collected at a spectral range of $450-4000 \mathrm{~cm}^{-1} 13$.

\section{Entrapment Efficiency (\%EE)}

The mixture was centrifuged for 70 minutes at $14000 \mathrm{rpm}$, the supernatant containing free Quercetin was obtained, and the absorbance was measured using HPLC. The entrapment efficiency of liposomes was determined by the following formula: $\mathrm{EE}(\%)=\left\{\left(C_{i}-C_{f}\right) / C_{i}\right\} \times 100$ where $\mathrm{EE}$ is the concentration of entrapped sample $(\mathrm{mg} / \mathrm{mL}), C_{i}$ is the initial concentration of sample used in formulating the liposomes $(\mathrm{mg} / \mathrm{mL}), C_{f}$ is the concentration of sample in the supernatant $(\mathrm{mg} / \mathrm{mL})$, and $E E(\%)$ is the percentage of the sample's entrapment ${ }^{15}$.

\section{Cytotoxicity Study on Ovarian Cancer and Human Embryonic Kidney Cells}

SKOV-3 and HEK293T $\left(1 \times 10^{5}\right)$ cells $(100 \mu l$ of cell suspension per well) were seeded in 96-well plates and incubated inside a $\mathrm{CO}_{2}$ incubator for 24 hours before 
treatment. They were treated separately with freshly prepared $1 \mathrm{mg} / \mathrm{ml}$ stock solution of Liposomal formulations of Quercetin (QTLF1-QTLF8), with doses of $50 \mu \mathrm{g}, 100 \mu \mathrm{g}$ and $200 \mu \mathrm{g}$ for 24 hours at $37^{\circ} \mathrm{C}$ in a humified atmosphere containing $5 \% \mathrm{CO}_{2}$ in air. Untreated cells served as control. At the end of treatment, $20 \mu \mathrm{l}$ of MTT [3-(4,5-dimethylthiozol-2-il)-2,5-2,5-

dipheniltetrazoliumbromide] was added to each well and incubated for another 4 hours at 37-degree $\mathrm{C}$ in a $\mathrm{CO}_{2}$ incubator. The MTT assay is a colorimetric assay for measuring the activity of enzymes that reduce MTT to formazan dyes, giving a purple color. A solubilizing solution DMSO (Dimethyl sulphoxide) $100 \mu$ l is added to dissolve the insoluble purple formazan product into a colored solution. The absorbance was taken at $570 \mathrm{~nm}$ by micro plate manager (Reader Type: Model 680 XR BioRad laboratories Inc.) ${ }^{16}$.

\section{Statistical Analysis}

This was done by Student's t-test $P<0.05$ was considered as significant. The percentage cell inhibition was calculated by the following formula: \% Cell Inhibition: 100 X (O. D of Control - O. D of Treated)/ O. D of Control Where O. D= Optical Density

\section{RESULTS}

\section{Preparation of Standard Curve of Quercetin in Ethanol at 370nm}

The Quercetin solutions $(2 \mu \mathrm{g} / \mathrm{ml}, 4 \mu \mathrm{g} / \mathrm{ml}, 6 \mu \mathrm{g} / \mathrm{ml}, 8 \mu \mathrm{g} / \mathrm{ml}$ and $10 \mu \mathrm{g} / \mathrm{ml}$ ) dissolved in ethanol were scanned in UV Visible Spectrophotometer (UV 1800, Shimadzu, Japan) at 200-400nm. Then absorbance was measured by UV Spectrophotometry at $370 \mathrm{~nm}$ wavelength using ethanol as blank. A graph was plotted keeping the concentrations in the $\mathrm{X}$-axis and the absorbance found in the $\mathrm{Y}$-axis.

\section{Preparation of Standard Curve of Quercetin in Phosphate buffer pH 7.4 at 370nm}

The quercetin solution $(5 \mu \mathrm{g} / \mathrm{ml}, 10 \mu \mathrm{g} / \mathrm{ml}, 15 \mu \mathrm{g} / \mathrm{ml}$, $20 \mu \mathrm{g} / \mathrm{ml}$ and $25 \mu \mathrm{g} / \mathrm{ml}$ dissolved in phosphate buffer $\mathrm{pH}$ 7.4) was scanned in UV Visible spectrophotometer (UV 1800, Shimadzu, Japan) at 200-400nm. Then absorbance was measured by UV Spectrophotometry at $370 \mathrm{~nm}$ wavelength using phosphate buffer as blank.

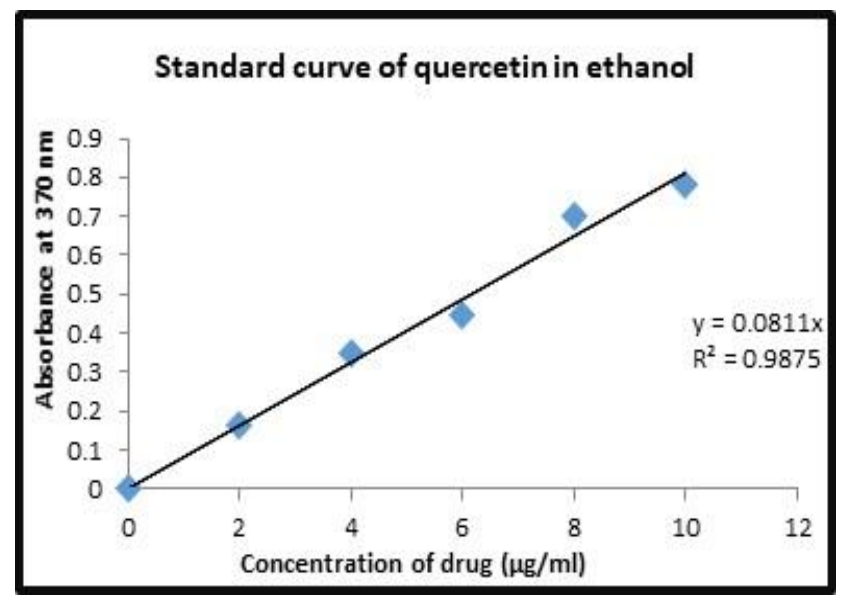

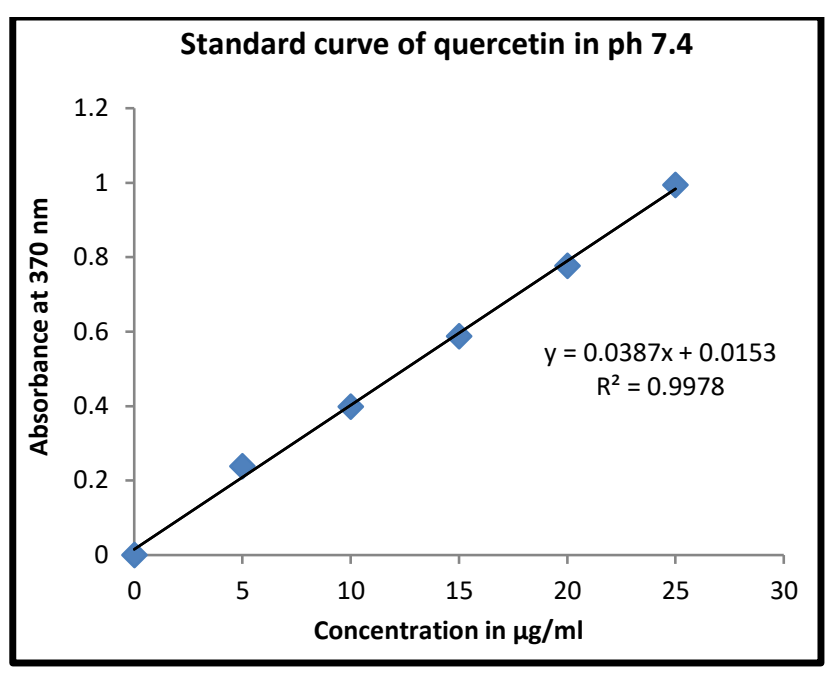

Figure 1: Standard Curves of Quercetin in Ethanol and $\mathrm{pH}$ 7.4. The concentration is plotted in the $X$-axis and the Absorbance in the $Y$-axis. The graphs give us $R^{2}$ values of 0.9875 and 0.9978 respectively.

Table 2: Standard Curve of QTF in Ethanol

\begin{tabular}{c|c|c|c|c|}
$\begin{array}{c}\text { Concentration } \\
(\mu \mathrm{g} / \mathrm{ml})\end{array}$ & \multicolumn{3}{|c|}{ Absorbance } & $\begin{array}{c}\text { Average } \pm \\
\text { S.D. }\end{array}$ \\
\hline 2 & $\mathbf{1}^{\text {st }}$ & $\mathbf{2}^{\text {nd }}$ & $\mathbf{3}^{\text {rd }}$ & . \\
\hline 4 & 0.156 & 0.162 & 0.169 & $0.162 \pm 0.005$ \\
\hline 6 & 0.331 & 0.353 & 0.360 & $0.348 \pm 0.012$ \\
\hline 8 & 0.439 & 0.452 & 0.445 & $0.445 \pm 0.005$ \\
\hline 10 & 0.697 & 0.699 & 0.707 & $0.701 \pm 0.004$ \\
\hline
\end{tabular}

Table 3: Standard Curve of QTF in Phosphate Buffer $\mathrm{pH}$ 7.4

\begin{tabular}{|c|c|c|c|c|}
\hline $\begin{array}{c}\text { Concentration } \\
(\mu \mathrm{g} / \mathrm{ml})\end{array}$ & $\mathbf{1}^{\text {st }}$ & $\mathbf{2}^{\text {nd }}$ & $\mathbf{3}^{\text {rd }}$ & Average \pm S.D. \\
\hline 5 & 0.237 & 0.238 & 0.240 & $0.238 \pm 0.0012$ \\
\hline 10 & 0.403 & 0.405 & 0.389 & $0.399 \pm 0.007$ \\
\hline 15 & 0.583 & 0.589 & 0.592 & $0.588 \pm .0037$ \\
\hline 20 & 0.771 & 0.778 & 0.782 & $0.777 \pm .0045$ \\
\hline 25 & 0.996 & 0.994 & 0.993 & $0.994 \pm 0.0012$ \\
\hline
\end{tabular}

\section{Identification of Quercetin by FTIR}

Fourier Transform Infrared Spectroscopy (FTIR) of pure drug was taken using FTIR spectrophotometer. The sample was prepared with potassium bromide and data were collected at a spectral range of $500-4000 \mathrm{~cm}^{-1}$.

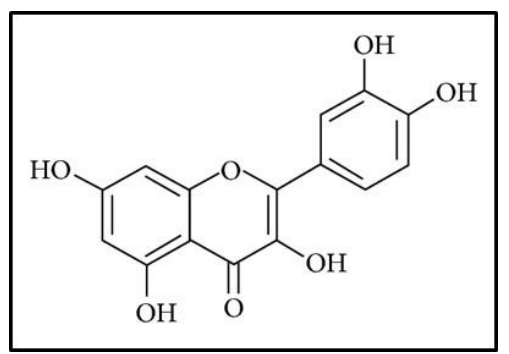

Figure 2: Structure of Quercetin 


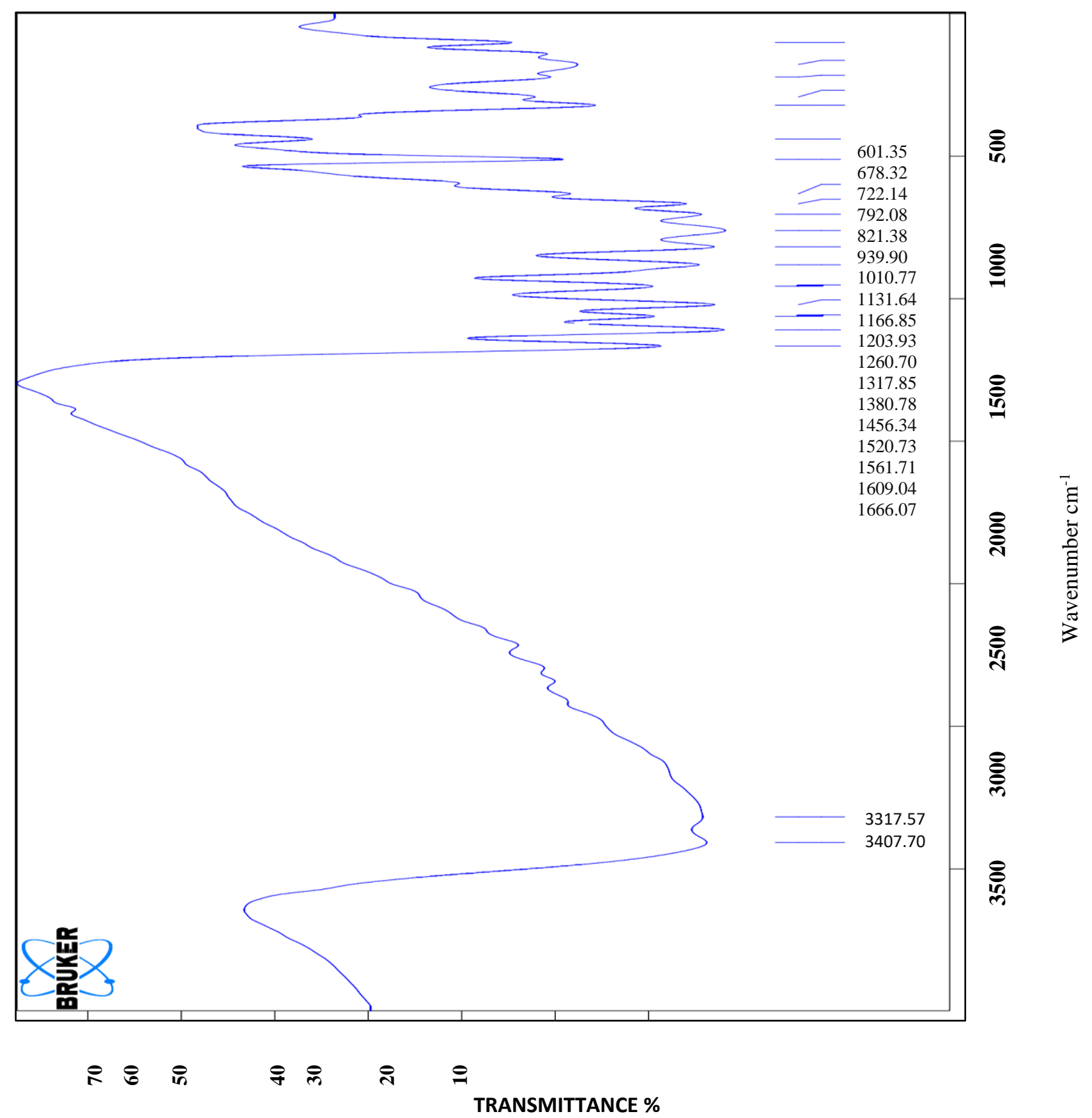

Figure 3: FTIR Spectrum of Quercetin

The peaks obtained were at $3407.70 \mathrm{~cm}^{-1}, 3317.57 \mathrm{~cm}^{-1}$, $1666.07 \mathrm{~cm}^{-1}, 1609.04 \mathrm{~cm}^{-1}, 1561.71 \mathrm{~cm}^{-1}, 1520.73 \mathrm{~cm}^{-1}$, $1456.34 \mathrm{~cm}^{-1}, 1380.78 \mathrm{~cm}^{-1}, 1317.85 \mathrm{~cm}^{-1}, 1260.70 \mathrm{~cm}^{-1}$, $1203.93 \mathrm{~cm}^{-1}, 1166.85 \mathrm{~cm}^{-1}, 1131.64 \mathrm{~cm}^{-1}, 1010.77 \mathrm{~cm}^{-1}$, $939.90 \mathrm{~cm}^{-1}, 821.38 \mathrm{~cm}^{-1}, 792.08 \mathrm{~cm}^{-1}, 722.14 \mathrm{~cm}^{-1}$, $678.32 \mathrm{~cm}^{-1}$ and $601.35 \mathrm{~cm}^{-1}$. The peak at $1380.78 \mathrm{~cm}^{-1}$ shows $\mathrm{O}-\mathrm{H}$ bending and that at $3407.70 \mathrm{~cm}^{-1}$ show $\mathrm{O}-\mathrm{H}$ stretching of phenolic groups. The peak at $1520.73 \mathrm{~cm}^{-1}$ points out the presence of aromatic $\mathrm{C}=\mathrm{C}$ stretching and that at $939.90 \mathrm{~cm}^{-1}$ is responsible for aromatic $\mathrm{C}=\mathrm{C}$ bending. The peaks at $1456.34 \mathrm{~cm}^{-1}$ is responsible for inplane aromatic $\mathrm{C}-\mathrm{H}$ bending and at $722.14 \mathrm{~cm}^{-1}$ leads to presence of out of plane bending of aromatic $\mathrm{C}-\mathrm{H}$ bond. $\mathrm{C}=\mathrm{O}$ stretching is detected by the presence of sharp peak at $1666.07 \mathrm{~cm}^{-1}$.

\section{Entrapment Efficiency}

The entrapment efficiency of liposomes was determined by the following formula:

$$
\mathrm{EE}(\%)=\left\{\left(C_{i}-C_{f}\right) / C_{i}\right\} \times 100,
$$

where $\mathrm{EE}$ is the concentration of entrapped sample $(\mathrm{mg} / \mathrm{mL}), C_{i}$ is the initial concentration of sample used in formulating the liposomes $(\mathrm{mg} / \mathrm{mL}), C_{f}$ is the concentration of sample in the supernatant $(\mathrm{mg} / \mathrm{mL})$, and $\mathrm{EE}(\%)$ is the percentage of the sample's entrapment. The entrapment efficiencies were found to decrease with the increase in the amounts of lipid. 
Table 4: Entrapment Efficiency of Quercetin Liposomal Formulation

\begin{tabular}{|c|c|c|c|c|c|}
\hline Code & Drug (mg) & Lipid $(\mathbf{m g})$ & $\begin{array}{c}\text { Initial Conc. } \\
\text { in } \mathbf{m g} / \mathbf{m l}\left(\mathbf{C}_{\mathbf{~}}\right)\end{array}$ & $\begin{array}{c}\text { Final Conc. in } \\
\mathbf{m g} / \mathbf{m l}\left(\mathbf{C}_{\mathbf{f}}\right)\end{array}$ & EE (\%) \\
\hline QTLF1 & 20 & 80 & 1.00 & 0.1214 & 87.86 \\
\hline QTLF3 & 20 & 150 & 1.00 & 0.1653 & 83.47 \\
\hline QTLF5 & 20 & 200 & 1.00 & 0.1705 & 82.95 \\
\hline QTLF6 & 20 & 234 & 1.00 & 0.1912 & 80.88 \\
\hline QTLF4 & 20 & 270 & 1.00 & 0.2997 & 70.03 \\
\hline QTLF2 & 25 & 75 & 1.25 & 0.3049 & 75.60 \\
\hline QTLF7 & 40 & 270 & 1.00 & 0.2093 & 79.07 \\
\hline QTLF8 & 30 & 200 & 1.00 & 0.1681 & 83.19 \\
\hline
\end{tabular}

\section{Cytotoxicity Study on Ovarian Cancer and Human Embryonic Kidney Cells}

The cytotoxic effects of the formulations (QTLF1-QTLF8) were checked on human ovarian cancer cells SKOV-3 by MTT Assay. All the formulations were found to have inhibitory effect on ovarian cancer cells after 24 hours of treatment. QTLF5 and QTLF8 showed slightly higher cytotoxicity as compared to the rest. So, it is reasonable to assume that if treated for more hours, a stronger inhibitory action will be observed. Whereas cytotoxic effects of the formulations (QTLF1-QTLF8) were checked on human embryonic kidney cells HEK293T by MTT Assay to analyze the effects of drug on normal cells. The formulations showed insignificant toxic effect on the cells. The O.D. values at $570 \mathrm{~nm}$ were plotted against the concentrations of $50 \mu \mathrm{g}, 100 \mu \mathrm{g}$ and $200 \mu \mathrm{g}$. All eight formulations were found to show an inhibition of below 30\% which is considered safe for administration. Hence, one can conclude that it does not cause toxicity to healthy human cells.

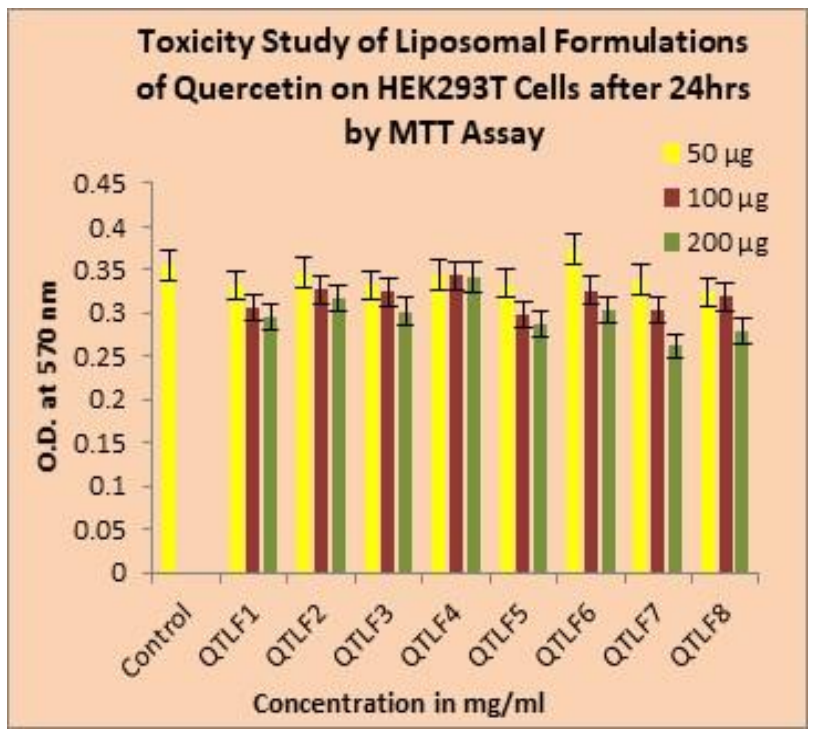

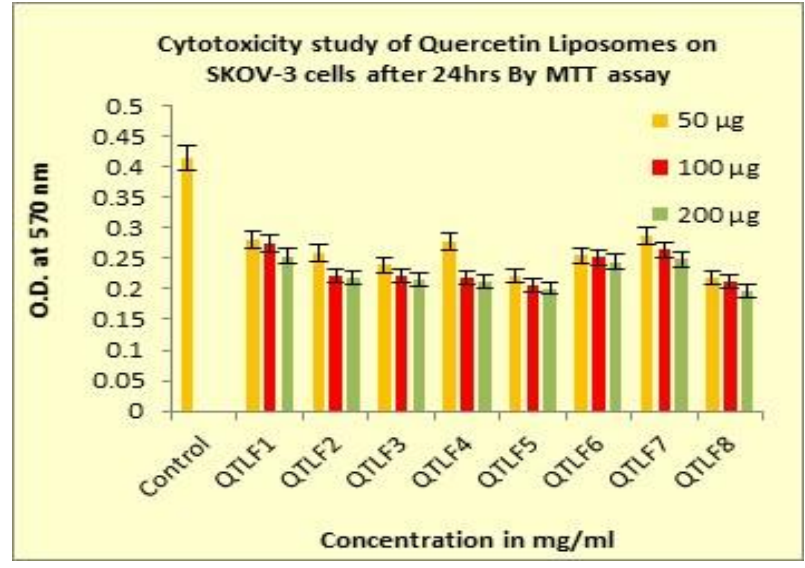
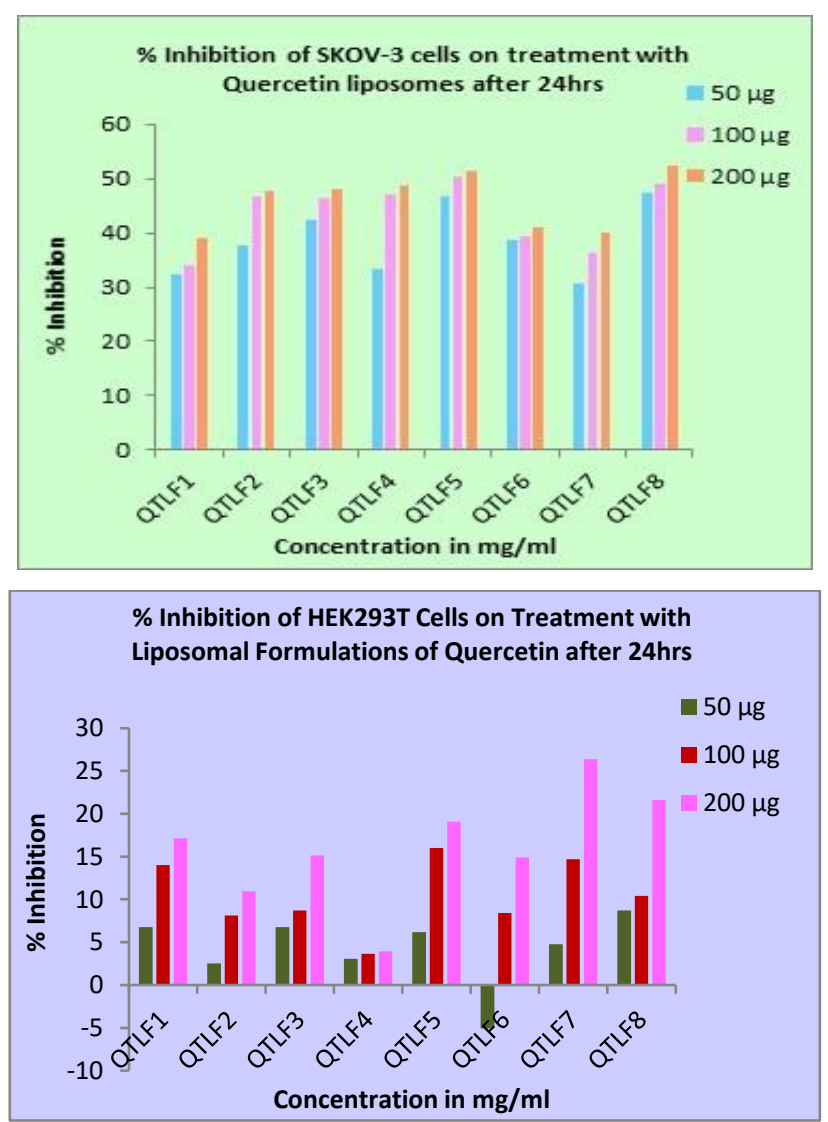

Figure 4: Histograms show the effect of QTLF1-QTLF8 on SKOV-3 cells and on HeK293T cell line by MTT Assay after 24 hours. Reduction in the O.D. values and increase in \% 
inhibition is observed in a concentration dependent manner. Data are mean \pm S.E.M. The highest inhibition on SKOV-3 cells was shown by QTLF5 and QTLF8 whereas the rest showed moderate cytotoxicity. All the formulations show effects below toxicity level on HEK293T cells, QTLF4 being the least toxic.

\section{DISCUSSION}

Quercetin is a chemo preventive agent of natural origin and is known to cause apoptosis or cell cycle arrest. It has shown efficiency of various types of cancer such as that of prostrate, cervical, lung, breast and colon. ${ }^{16}$ Quercetin is a potential candidate for treatment of ovarian cancer but the disadvantages associated with it are low water solubility and hence poor systemic bioavailability. So, it is necessary to incorporate it into suitable delivery system and yield a suitable pharmaceutical dosage form. ${ }^{17}$ Liposomes are carriers which can provide effective cancer treatment on incorporation of flavonoids, eliminating adverse effects of chemotherapy. Liposome bound drugs show an increase in bioavailability and hence leads to proper cancer treatment. ${ }^{[18,19]}$ Hence, in this study, a liposomal formulation of Quercetin is prepared to check the activity on human ovarian cancer cell line, SKOV-3. The toxicological screening of the formulations are done on human embryonic kidney cell line, HEK293T, which is often used in research fields for determination of adverse effects of drugs on normal healthy cells. ${ }^{12}$

On determining the entrapment efficiency, QTLF1 showed the maximum percentage whereas QTLF4 showed the least value. The cytotoxic activity was observed on human ovarian cancer cells SKOV-3.The formulations (QTLF1QTLF8) showed a satisfactory cytotoxic activity on SKOV-3 cell line after 24 hours which indicates stronger effect after 48 or 72 hours of exposure. QTLF5 and QTLF8 were found to show slightly higher inhibitory effect on the ovarian cancer cells. Further, a toxicity study was performed on Human Embryonic Kidney cells (HEK293T). The formulations (QTLF1-QTLF8) have not shown a toxic effect on healthy cells and hence were considered safe for administration into body. QTLF4 shows the least toxicity among all the formulations.

\section{Summary \& Conclusion}

Quercetin is a poly-phenolic compound which bears high antioxidant, anti-tumor and cytotoxic activity which is crucial to fight different types of cancer. It is useful in treatment of quite a number of cancers like breast, colon, cervical, etc. However, it belongs to BCS Class IV which is why it has low solubility in aqueous media and limited bioavailability in systemic circulation. Being a natural flavonoid, Quercetin is devoid of extreme harmful effects and can be considered a much safer candidate for treatment of cancer. So, overcoming its limitations is the most essential approach in giving rise to a major breakthrough in cancer therapy.

Novel Drug Delivery is a unique approach which leads to formulations of small particle size with better solubility, higher bioavailability and efficient targeting at the site of action. Novel drug delivery formulations can be prepared by modifying the release kinetics of drug in the body by incorporation into lipid matrices or in suitable polymers such as liposomes, nanoparticles, phytosomes etc. The drug under consideration, Quercetin can be considered a good candidate to be converted into a novel formulation by incorporation into a lipid carrier. The choice of novel carrier was Liposome, a lipid matrix composed of phospholipids with a hydrophilic head and a lipophilic tail. Liposomes structurally represent the biological membranes and hence are biocompatible and nonimmunogenic. It is capable of incorporating both lipophilic and hydrophilic drugs into it and gets accumulated in the vicinity of tumors once administered. This results in a strong and prolonged pharmacological action thereby making liposomes, the novel carrier of choice for the study.

Cancer is a result of gene mutations characterized by abnormal cell growth and proliferation leading to some serious health hazards. This occurs by various factors like gene mutations, smoking, environmental factors etc. This study focuses on ovarian cancer. It is a type of cancer frequently seen in women affecting the gynecological processes, although this type of cancer whose early detections are yet to be discovered and thereby is a prime cause of death in women. Oral contraceptives and certain synthetic anti-cancer drugs have been used for the treatment but have given rise to side effects. Hence, efforts are frequently given by researchers to increase natural drug formulations in market which can be equally effective but with reduced side effects.

The free drug Quercetin had to undergo initial identification tests wherein standard curves were prepared and FTIR spectra of the drug was analyzed. Eight liposomal formulations of Quercetin within different drug and lipid ratios were prepared by hand shaking method and stored for characterization. The entrapment efficiencies of the formulations were determined. The prepared liposomes (QTLF1-QTLF8) were then used for invitro studies to check the cytotoxic activity on the human ovarian cancer cell (SKOV-3). Toxicity studies of all eight formulations were conducted on normal human cells, namely human embryonic kidney cells (HEK293T). Kidney is a vital organ involved in filtration of blood, formation of urine, maintaining homeostasis etc. in our body. Kidney cells are delicate and prone to drug adverse effects thereby disrupting the normal functioning of the human body. Thus, the human embryonic kidney cells were selected for examining the toxicity causing capabilities of the liposomal formulations of Quercetin.

Hence, it can be concluded that in the ovarian cancer cells, the liposomal preparations of Quercetin show cytotoxic activity after a treatment for 24 hours, so it is found to be effective for treating ovarian cancer. The toxicity studies on normal human cells i.e., human embryonic kidney cells, proved the formulations to be safe for administration into human body. So, a further conclusion can be drawn that by 
incorporating the drug into the lipid carrier, the activity of the drug was found to improve and hence the solubility enhancement effectively intensifies the cytotoxic activities of Quercetin by correcting the solubility issues.

Acknowledgement: The authors of this paper are very much thankful to Council of Scientific and Industrial Research, Indian Institute of Chemical Biology (CSIR-IICB), Kolkata for providing the funding to perform the research work and also NSHM Knowledge Campus, Kolkata-Group of Institutions, where a portion of the study was conducted.

\section{REFERENCES}

1. Das S., Hussain A. , Verma P.R.P, Imam S. S., Altamimi Mohammad A, Alshehri S., Singh S. K., Recent Advances in Liposomal Drug Delivery System of Quercetin for Cancer Targeting: A Mechanistic Approach. Current Drug Delivery, 17(1), 2020, 6.

2. Faheem A. M. and Abdelkader D. H., Novel drug delivery systems. Engineering Drug Delivery Systems, 2020, pp: 1-16.

3. Pucci C., Martinelli C., and Ciofani G., Innovative approaches for cancer treatment: current perspectives and new challenges. Ecancermedical science, 13, 2019, 961.

4. He K., Tang M., Safety of Novel Liposomal Drugs for Cancer Treatment: Advances and Prospects. Chemico-Biological Interactions, 2017, pp: 1-23.

5. Kakde D., Jain D., Shrivastava V., Kakde R. and Patil A. T., Cancer Therapeutics- Opportunities, Challenges and Advances in Drug Delivery. Journal of Applied Pharmaceutical Science, 01 (09), 2011, 01-10.

6. Hassanpour S. H., Dehghani M., Review of cancer from perspective of molecular. Journal of Cancer Research and Practice, 4 (4), 2017, 127-129.

7. Senapati S., Mahanta A. K., Kumar S. and Maiti P., Controlled drug delivery vehicles for cancer treatment and their performance. Signal Transduction and Targeted Therapy, 3(7), 2018, 1-19.

8. Lee Jung-Min, Minasian Lori, Kohn Elise C., New strategies in ovarian cancer treatment. Cancer, 125 (S24), 2019, 46234629.

9. Song Y. S., Kim H. S., Aoki D., Dhanasekaran D. N. and Tsang B. K., Ovarian Cancer. BioMed Research International, 764323, 2014, 1-2.
10. Chien J. and Poole E. M., Ovarian cancer prevention, screening and early detection: Report from the $11^{\text {th }}$ Biennial Ovarian Cancer Research Symposium. Int J Gynecol Cancer, 27(9), 2017, S20-S22.

11. Modugno F. and Edwards R. P., Ovarian Cancer: Prevention, Detection and Treatment of the Disease and Its Recurrence. Molecular Mechanisms and Personalized Medicine Meeting Report, Int J Gynecol Cancer, 22(8), 2012, S45-S57.

12. Hu, J., Han, J., Li, H., Zhang, X., Liu, L. lan, Chen, F., \& Zeng, B., Human Embryonic Kidney 293 Cells: A Vehicle for Biopharmaceutical Manufacturing, Structural Biology, and Electrophysiology. Cells Tissues Organs, 205, 2018, 1-8.

13. N. Kendre Prakash, V. Pande Vishal and M. Chavan Kishori, Novel Formulation Strategy to Enhance Solubility of Quercetin. Pharmacophore, 5 (3), 2014, 358-370.

14. Rao Monica R. P. and Laxmi S. B., Liposomal Drug Delivery for Solubility and Bioavailability Enhancement of Efavirenz. Indian J Pharm Sci. 80(6), 2018, 1115-1124.

15. Bahareh S., Ibrahim N. M., Shaharuddin, Development and Characterization of Liposomal Doxorubicin Hydrochloride with Palm Oil. BioMed Research International, 2, 2014, 765426.

16. Besra A. R., Pal K., Basu S., Besra S. E., Anti-tumor activities of secretion extract of Bellamya bengalensis in human hepatocellular carcinoma cell lines is mediated by caspasedependent apoptosis and cell cycle arrest. World Journal of Pharmacy and Pharmaceutical Sciences, 4 (10), 2015, 23262344.

17. Jeong J. H., An J. Y., Kwon Y. T., Rhee J. G., and Lee Y. J., Effects of low dose quercetin: Cancer cell-specific inhibition of cell cycle progression. J Cell Biochem, 106(1), 2009, 7382.

18. Xu, G., Li, B., Wang, T., Wan, J., Zhang, Y., Huang, J., \& Shen, $Y$., Enhancing the anti-ovarian cancer activity of quercetin using a self-assemblin. RSC Adv., 8, 2018, 21229.

19. Das, A., Konyak, P. M., Das, A., Dey, S. K., \& Saha, C., Physicochemical characterization of dual action liposomal formulations: anticancer and antimicrobial. Heliyon, 5, 2019, e02372.

Source of Support: None declared.

Conflict of Interest: None declared.

For any question relates to this article, please reach us at: editor@globalresearchonline.net New manuscripts for publication can be submitted at: submit@globalresearchonline.net and submit_ijpsrr@rediffmail.com 